\title{
Folia, mediações e megaeventos: \\ breve estudo sobre as representações do Carnaval 2010 nos jornais cariocas
}

\section{Ricardo Ferreira Freitas}

\section{Resumo:}

A proposta deste artigo é contribuir com a discussão sobre a vocação do Rio de Janeiro para abrigar megaeventos, levando especialmente em consideração o tratamento midiático desenvolvido nesses períodos sobre a violência urbana. Além da oportunidade de confraternização, esses eventos representam importante fonte de divisas e de negócios. Nos últimos tempos também têm sido utilizados para consolidar políticas públicas de segurança. Para compreender melhor esse quadro, recorremos a teóricos como Bauman e Maffesoli, atentos às questões da violência e dos ajuntamentos urbanos. A análise da cobertura do Carnaval de 2010 do Rio de Janeiro demonstra a tendência de priorizar a programação do megaevento no lugar dos assuntos abordados no cotidiano dos jornais. Essa estratégia parece reforçar a idéia de que a cidade está preparada para os megaeventos futuros.

\section{Palavras Chave:}

Carnaval, violência, mídia impressa, megaeventos.

\section{Abstract:}

The purpose of this paper is to contribute to the discussion on the vocation of Rio de Janeiro to host mega events, especially taking into account the media treatment of urban violence in these periods. Besides the opportunity of congregating, such events represent an important source of incomings and businesses. Recently they have also been used to strengthening public safety policies. To better understand this situation, we turn to theorists such as Bauman and Maffesoli, attentive to issues of violence and urban gatherings. The analysis of Rio de Janeiro's 2010 Carnival coverage shows a tendency to prioritize the scheduling of the mega event instead of the matters addressed in daily newspapers. This strategy seems to reinforce the idea that the city is prepared for future mega events.

\section{Keywords:}

Carnival, violence, print media, mega events.

"(...) existe animação social quando estamos dispostos ao Outro. Talvez seja assim que devamos pensar as 'viscosidades' que não faltam em nossa atualidade. Aquilo que, nos fenômenos esportivos, musicais, religiosos, turísticos, leva a grudar no outro, a imitá-lo, a procurar sua presença, inclusive naquilo que em dado momento tende a negar o indivíduo. Este reencontra nesses ajuntamentos uma parte de si mesmo, uma ou outra de suas próprias possibilidades que não podem ser expressas em sua identidade profissional, sexual ou ideológica" (MAFFESOLI, 2004: 94).

O Rio de Janeiro é uma das cidades que mais abriga eventos em todo o mundo. De pequenos a mega, eles 
podem ser de ordem política, acadêmica, esportiva, artística, entre tantas outras. Além da oportunidade de confraternização, esses eventos representam importante fonte de divisas e de negócios. Nos últimos tempos também têm sido utilizados para consolidar políticas públicas de segurança, como vemos nas coberturas jornalísticas dos jornais impressos entre os últimos meses de 2009 e os primeiros de 2010. Como o megaevento vende muita coisa, ele significa uma importante ocasião para a mídia.

O Rio de Janeiro é representado em todo o mundo por uma série de características da ordem do belo e, ao mesmo tempo, por uma variedade de questões ligadas à violência. Reconhecida como uma cidade de festas e com um povo sorridente, o Rio de Janeiro é comumente associado a eventos como o Reveillon e o Carnaval. Atualmente, esses são dois momentos da cidade em que ela reencontra sua autoestima, tão em baixa no resto do ano devido aos problemas de miséria, violência urbana, habitação, trânsito. Nesses dois períodos, a metrópole recebe milhares de visitantes e se alegra com isso.

Neste artigo, discutimos o papel dos megaeventos no imaginário carioca, a partir de suas representações na mídia, mais especificamente nas primeiras páginas e nas editorias de cidade nas versões impressas de O Globo e do Jornal do Brasil durante o Carnaval de 2010. Iniciamos com uma breve discussão sobre a vocação do Rio de Janeiro para abrigar eventos de grande porte e discutimos as representações da mídia impressa carioca sobre o Carnaval de 2010. A idéia é lançar algumas pistas sobre a forma como a imprensa tem tratado os megaeventos na cidade, deixando de lado um dos argumentos mais utilizados em suas páginas ao longo do ano: a violência.

Objetivamos estudar a mudança no teor das narrativas sobre a violência em períodos de megaeventos nos últimos meses de 2009 e nos primeiros de 2010, desde que o governo do Estado do Rio de Janeiro efetuou intervenções policiais de grande porte em comunidades onde o tráfico de drogas comandava as normas locais. Essas comunidades estão próximas aos lugares onde acontece a maior festa de Réveillon no Rio de Janeiro, a Praia de Copacabana.

Como percebido no Reveillon de 2009-2010, os dois jornais escolhidos elegeram, como pauta, a pacificação dos morros da zona sul do Rio e as tragédias decorrentes do excesso de chuvas em Angra dos Reis e outras cidades do país, em vez de abordar a violência no Rio. Pelo registro desses veículos, uma leitura possível seria que não houve violência na cidade na noite da passagem do ano. No Carnaval, megaevento analisado neste artigo, a violência na cidade também não foi matéria de primeira página, apesar de aparecer pontualmente na editoria Rio de $O$ Globo e no caderno Cidade do Jornal do Brasil.

\section{Os megaeventos, a mídia e o imaginário carioca}

"De que maneira chegaremos / Às brancas portas da Via-Láctea? / Será com asas ou com remos? / Será com os músculos com que saltas? / (...) Seremos pássaros ou anjos / atravessando a sombra da tarde! / (...) Sem nada de humanos assuntos: / muito mais puros, muito mais graves!" (Trapezista - Jogos Olímpicos, MEIRELES, 1972: 259).

Na contemporaneidade, um emaranhado de novas tecnologias habita, e muitas vezes constitui, a rede de comunicações em que se baseia o evento, sendo, em alguns casos, essa rede mais importante que o próprio certame em questão. Horários e locais são escolhidos em função da possibilidade de midiatização do acontecimento, por exemplo. Quanto mais infra-estrutura de comunicação tiver uma cidade, mais eventos ela receberá. Não raramente, os eventos são vistos tanto por empresários quanto por atletas e artistas como uma grande oportunidade de dar visibilidade a seu negócio, tornando o espetáculo, assim, mais significativo que a própria atividade em si.

Fenômeno de comunicação, os megaeventos habitam o imaginário urbano, marcam a memória do lugar, 
redesenham a cidade e se inscrevem na vida cotidiana, criando e alimentando uma importante rede de comunicação urbana. A cidade, a população, o trânsito, a arquitetura, a saúde, a segurança pública - todos os aspectos da vida urbana podem se movimentar em função da sua realização. O turismo é oxigenado e novas oportunidades de empregos efetivos e temporários são oferecidas. Nos âmbitos corporativo e acadêmico, congressos, seminários e feiras propõem novos produtos e novas discussões que podem modificar um panorama, tornando-se determinante para a área de conhecimento envolvida.

Michel Maffesoli (2004: 32-58) atribui especial importância à observação de grandes ajuntamentos e dos excessos característicos das efervescências sociais. Nesses eventos desenvolve-se um tipo de sociabilidade onde não se deseja compreender, nem conhecer profundamente o outro, saber dos seus atributos pessoais ou financeiros. Por algumas horas ou alguns dias os problemas do cotidiano ficam em segundo plano, pois o primeiro é encontrar os amigos, se unir ao desconhecido e dançar junto, torcer junto ou até reclamar junto. Tanto faz. O importante é estar junto. Revela-se, para o autor, um caminho ousado, mas muito interessante para os estudos da sociedade contemporânea.

Festas, celebrações e rituais sempre estiveram presentes em diferentes culturas, desde as mais primitivas épocas. A denominação "mega" dos eventos é explicada por Malena Segura Contrera e Marcela Moro (2008: 1-12) como um recurso publicitário que seduz o público à concentração massiva em um mesmo espaço. A estrutura e a intensidade das festas e celebrações foram modificadas na Modernidade, dentro do contexto da cultura de massa e da estética por ela imposta. O século XX consolidou uma nova percepção do mundo proposta por um cotidiano repleto de urgências. O homem contemporâneo recebe estimulações nervosas e mergulha numa profusão de imagens e textos, "hiperestímulo da nova dinâmica da vida humana urbana, permeada pela velocidade associada à multiplicação desenfreada dos contatos mediatizados" (CONTRERA \& MORO, 2008: 2).

Na primeira década do século XXI, os megaeventos orientam políticas urbanas, maquiando a estética urbana ou mesmo fortalecendo tendências ou vocações. As duas possibilidades sempre estão presentes. A imprensa tem papel fundamental, como preconiza sua ética, mas, na verdade, vive refém das questões políticas e financeiras.

Tratando-se de Rio de Janeiro, a violência urbana é um tema recorrente na mídia. A imagem do Rio está associada à violência, mas a cidade e os megaeventos atraem cada vez mais pessoas de todo o mundo. Em geral associado ao Carnaval e ao Reveillon, o Rio de Janeiro recebe milhares de turistas durante todos os meses do ano. No entanto, a idéia de cidade violenta e perigosa se consolida como uma das primeiras características lembradas por turistas estrangeiros e brasileiros. Curiosamente, esse medo não diminui a importância e a grandeza dos megaeventos nela sediados, como pôde ser observado no Reveillon em Copacabana e durante o Carnaval de 2010. Percebemos, na análise dos jornais durante o Carnaval, que a mídia aposta na festa e a representa como mais importante do que os problemas, mostrando bem que o imaginário carioca é pautado pela alegria de estar-junto, como diria Maffesoli, que, aliás, cita comumente o Brasil e, em especial, o Rio de Janeiro, como laboratórios da pós-modernidade (1990 e 2007) por serem lugares que misturam tradição e efemeridade sem traumas. É claro que a imprensa também está pautada, no caso do Carnaval e do Réveillon, por interesses políticos e econômicos, especialmente depois do Rio ter sido escolhido sede das Olimpíadas de 2016.

\section{A mídia, a violência urbana e as representações sociais}

"Muitos indícios característicos da vida contemporânea contribuem para um sentimento esmagador de incerteza, para uma visão do futuro do 'mundo como tal' e do mundo privado, o 'mundo que está próximo', como essencialmente indecidivel, incontrolável e, portanto, aterrorizante, assim como para uma suspeita de que os atuais e já familiares marcos de ação não permanecerão constantes por tempo 
suficiente para permitir um cálculo correto dos efeitos de nossas ações..." (BAUMAN, 2008: 110).

Incerteza, medo e violência são alguns dos assuntos ou valores mais presentes na imprensa brasileira. Esses sentimentos, que vendem jornal e aumentam audiência, são amplamente utilizados seja como jornalismo-espetáculo seja como notícia stricto sensu.

Nossa proposta, neste pequeno artigo, é identificar e analisar as significações que são atribuídas à violência no Carnaval a partir da mediação jornalística. Nosso foco desloca-se das formas das estruturas narrativas, ou seja, do ato, para a análise das relações estabelecidas pela produção de sentidos do ato de narrar, uma vez que os discursos, por sua ampla visibilidade, orientam as práticas sociais. Nessa perspectiva, buscamos apoio no pensamento de Michel de Certeau (1994: 195-202), que nos fala da importância de desviar o olhar dos sistemas lingüísticos e privilegiar as práticas significativas.

Nossa pesquisa pertence a este tempo "segundo" da análise, que passa das estruturas às ações. Mas neste conjunto muito amplo vou considerar apenas ações narrativas. Elas permitirão precisar algumas formas elementares das práticas organizadoras de espaço: a bipolaridade "mapa" e "percurso", os processos de delimitação ou de "limitação" e as "focalizações enunciativas" (ou seja, o índice do corpo do discurso) (1994: 201).

É nesse turbilhão de novos recortes e práticas culturais que retomamos o pensamento de Émile Durkheim (1989: 40-210) e Marcel Mauss (1991: 20-50) e sua noção de representação coletiva que, segundo Chartier (1988), articula bem a ordenação da estrutura social. Durkheim foi um dos primeiros estudiosos sobre o tema. Seus trabalhos iniciais partiram da observação de tribos primitivas australianas que praticavam interessantes manifestações religiosas. O estudo dos seus ritos facilitava a compreensão de como eram estruturados outros tipos de sociedade. O sociólogo percebeu que essas tribos organizavam sua vida social para além do indivíduo, reconhecendo que a sociedade é organizada pela associação entre homens: "à medida que participa da sociedade, o indivíduo vai naturalmente além de si mesmo, seja quando pensa seja quando age" (DURKHEIM, 1989: 46). Revela-se, pois, o conceito de representações coletivas pelo qual se explica a religião, os mitos, a ciência, entre outros, como conhecimentos que já fazem parte de uma sociedade. Apesar das representações serem analisadas com a ajuda de símbolos, há que se ter cuidado na ação de sua compreensão, pois, conforme afirma Émile Durkheim, "é preciso saber atingir a realidade que ele figura e que lhe dá sua verdadeira significação" (1989: 206). Quando praticamos uma análise, estamos (re)apropriando as representações, já carregadas das percepções do grupo social do autor, e criando outras novas.

Para Elton Antunes e Paulo Bernardo Vaz (2006), os estudos sobre mídia devem ultrapassar os estudos dos meios, dos seus efeitos, e seguir em busca de compreender sua interseção, pois trabalhar com uma visão midiacêntrica desvaloriza a abordagem dos processos comunicativos. Os produtos midiáticos estabelecem formas interativas de representações que são partilhadas e que contribuem para estruturar o cotidiano. Este processo sugere a mídia como um elo que vincula o indivíduo ao seu processo, convocando todos os cidadãos ao compartilhamento de diferentes experiências.

A partir dessa opção metodológica para trabalhar com as representações midiáticas, escolhemos o Rio de Janeiro por ser uma cidade que acolhe diversos eventos de diferentes portes, recepcionando pessoas de várias partes do planeta, padecendo, ao mesmo tempo, com sua fama de violenta e insegura. É bem verdade que a situação de algumas cidades brasileiras não é a mais confortável no tocante à segurança. Por outro lado, é verdade também que o jornalismo policial melhorou muito de qualidade nos últimos anos (RAMOS \& PAIVA, 2007: 10-120), mas ainda peca por supervalorizar o crime em detrimento de outros acontecimentos. Hoje, os casos que envolviam sangue de forma apelativa nas páginas dos jornais deram lugar ao narcotráfico, às chacinas, às organizações criminosas globalizadas e à corrupção da 
polícia. Há melhor apuração dos episódios, mas não avançamos na correta valorização da violência enquanto notícia em relação aos outros fatos que acontecem na sociedade. O jornal $O$ Globo, por exemplo, ocupa hoje muito mais páginas com essa temática do que o fazia em 1990.

Neste artigo, trabalhamos mais especificamente com as narrativas em torno do Carnaval, devido ao número importante de turistas que transitam no evento e também pela expectativa da população em relação à violência nessas festas. Nossa intenção é compreender melhor esse quadro de lazer e pânico e inventariar os elementos mais presentes no discurso da mídia nessas situações. Para isso, trabalhamos com as matérias jornalísticas publicadas pelos jornais $O$ Globo e Jornal do Brasil, durante o Carnaval de 2010. A escolha desse evento se dá devido à mudança significativa nas abordagens do noticiário sobre a violência em relação aos outros anos. Apesar de ambos os jornais serem críticos em relação à administração estadual e municipal, percebemos que o fato de o Brasil, e mais especificamente o Rio de Janeiro, estar recebendo megaeventos de estrutura internacional como a Copa de 2014 e os Jogos Olímpicos de 2016, faz com que seja valorizada a cidade que dá certo em vez da representação sobre o cotidiano urbano que estamos habituados a ler nos jornais cariocas.

\section{Breve análise da cobertura de Carnaval de dois jornais cariocas}

\section{Sábado de Carnaval}

A primeira página do jornal $O$ Globo anuncia: "Rio a caminho do maior Carnaval de rua". A matéria faz referência ao exponencial crescimento do Carnaval de rua na cidade, competindo com o de Salvador. Segundo o jornal, estima-se em 2,5 milhões o número de foliões atrás de 465 blocos, constituindo-se, assim, como o mais populoso Carnaval de rua do Brasil. Isso implica mais turistas e divisas circulando na cidade, assim como maior mais atenção da mídia. Na mesma edição, nas páginas de opinião, artigo de Cristovam Buarque chama a atenção que os brasileiros estão eufóricos por receberem a Copa em 2014 e as Olimpíadas em 2016, mas não estão atentos para o fato de que em 2012, o Rio de Janeiro sediará o maior evento político deste início de século, a Rio+20, seguimento da grande cúpula de 1992.

Ainda no sábado, O Jornal do Brasil apresenta matéria na primeira página intitulada "O rico bloco dos investidores", informando que a Agência Brasileira de Promoção de Exportações e Investimentos APEX - convidou 150 empresários e formadores de opinião de 29 países para assistir ao desfile no Sambódromo do Rio e, principalmente, fechar bons negócios no país. Segundo o JB, a Apex conseguiu 10 milhões de investimentos estrangeiros no Brasil com essa iniciativa em 2009. A empreitada conta com a parceria da Embratur e de entidades empresariais de diversos setores da economia, com o objetivo de intensificar o relacionamento entre empresários brasileiros e compradores internacionais. Nos dias que antecedem e sucedem o Carnaval acontecem visitas a fábricas, lojas e pólos industriais em vários estados brasileiros.

\section{Domingo de Carnaval}

Entre as inúmeras matérias sobre o Carnaval, um título e uma chamada na primeira página de $O$ Globo se sobressaem: "Bloco bate recorde de público" e "Vende-se uma vaga de madrinha da bateria. A combinar". O bloco a que se refere a primeira matéria é o Cordão da Bola Preta que arrastou pelo centro do Rio, no dia anterior, 1,5 milhão de foliões, o maior público de seus 91 anos. Esse feito consolida o resgate da tradição dos blocos de rua na cidade, transformando-os em verdadeira opção de lazer para cariocas e turistas. Quanto à matéria sobre vagas para madrinha de bateria, novamente a mercantilização do Carnaval é abordada, desta vez tratando da compra do passe de rainhas de bateria por mulheres que 
querem aproveitar a exposição para incrementar suas carreiras.

No Jornal do Brasil, a primeira página de domingo não apresenta nenhuma matéria bombástica sobre o Carnaval. O destaque é a programação das escolas de samba e demais atividades da festa. No entanto, o caderno Cidade é praticamente todo voltado para o evento, com uma curiosa combinação de matérias e artigos, especialmente nas páginas 22 e 23. Na página 22, a multidão do Cordão da Bola Preta acotovela uma pequena nota sobre a morte de um assaltante morto em tiroteio com um policial. Abaixo, um artigo assinado pelo assessor de imprensa da Arquidiocese do Rio de Janeiro defende o Carnaval de rua. Na página ao lado, a da direita, o editor do caderno critica o negócio milionário no qual o Carnaval se transformou, especialmente a midiatização do desfile das escolas de samba, e encerra o texto feliz por saber que tudo isso acabará em poucos dias.

\section{Segunda de Carnaval}

A primeira página dos dois jornais tratam sobre o desfile da noite anterior. Ambos publicam uma pequena matéria política, mas é a festa que ocupa quase toda a página. Nenhuma referência aos negócios nem à violência. Ao folhearmos $O$ Globo, vemos pela primeira vez neste Carnaval duas notícias chocantes em relação ao evento: "Jovem é esfaqueado por assaltante durante desfile da Banda de Ipanema". Um rapaz de 20 anos foi esfaqueado no pescoço ao reagir a um furto. O subtítulo da reportagem é "Em dois dias de folia, 40 turistas foram furtados no Centro e na Zona Sul". Na página seguinte, uma outra reportagem de violência no Carnaval "Policial federal mata outro agente em festa de música eletrônica na Marina".

O caderno Cidade do JB também aborda a história do policial que matou o colega e do rapaz esfaqueado na Banda de Ipanema. Um terceiro assunto, na mesma matéria, chama a atenção: é o caso de uma menina entre 8 e 12 anos violentada e estrangulada no Aterro do Flamengo. No restante do jornal, matérias sobre urina nas ruas da cidade e coberturas da programação do Carnaval.

\section{Terça de Carnaval}

Assim como na segunda-feira, o enfoque principal na primeira página de ambos os jornais ficou por conta da cobertura do desfile das escolas de samba. As outras, de pequeno porte, falavam sobre política e o calor no Rio de Janeiro. Na editoria Rio do jornal $O$ Globo, boa parte dos problemas abordados era de temas corriqueiros aos cariocas como metrô, choque de ordem na orla, atropelamento, mas a última página desse caderno traz um pouco do habitual em relação à violência: "Seis ladrões invadem casa em Santa Teresa", denunciando que uma mesma casa foi assaltada pela segunda vez em menos de um ano. Duas outras matérias importantes tratam das notícias sobre a menina encontrada no Aterro e sobre o policial morto em festa.

No Jornal do Brasil, o caderno Cidade contou com apenas três páginas, duas das quais dedicadas aos novos postes químicos e ao cheiro de urina nas ruas. A terceira página foi preenchida pela coluna de Anna Ramalho.

\section{Quarta-feira de cinzas}


Tanto O Globo como o Jornal do Brasil se limitam, em suas primeiras páginas, a relatar o desfile das escolas de samba, apontando as favoritas ao título. Nenhuma chamada sobre negócios no Carnaval, nem sobre violência no dia anterior. Ao folhearmos a editoria Rio de $O$ Globo, o destaque ficou por conta do lixo e do cheiro de urina, assuntos, aliás, bastante presentes nas edições dos dias anteriores. Uma matéria, porém, chama a atenção na página 10, sob o título "Turistas aproveitam a onda carioca: Rio tem aumento de visitantes no Carnaval e já se prepara para 2011". Foram entrevistados turistas de diferentes partes do mundo e a abordagem ficou por conta do número recorde de ocupações nos hotéis. Os últimos parágrafos, porém, falam, de uma maneira bastante leve, sobre a violência aos turistas, basicamente roubos e furtos. Segundo a matéria, a Delegacia Especial de Apoio ao Turismo registrou uma média de dez reclamações por dia, número inferior ao de 2009. Mas é na última página da editoria Rio que percebemos que o clima de Carnaval começa a ser substituído pelo habitual enfoque na violência. Entre assuntos típicos do imaginário das grandes cidades como panes de energia elétrica, incêndio em apartamento, atropelamentos, motoristas alcoolizados, uma pequena matéria resume o que não havia sido dito até então - "Carnaval 2010: mais furtos do que em 2009. Bandidos agiam fantasiados para não serem reconhecidos". A reportagem diz que em todo o Estado do Rio de Janeiro foram registrados 799 furtos a transeuntes entre a manhã de sábado e a tarde de terça-feira nas delegacias legais. Já o número de roubos com violência sofreu uma queda considerável de 648 para 371 no Carnaval de 2010.

O caderno Cidade do Jornal do Brasil contou nesse dia com somente duas páginas que se limitaram a abordar a falta de choque de ordem na Praia Vermelha e na Urca, além da análise meteorológica do tempo e da coluna de Anna Ramalho.

\section{Outras considerações}

Os dois jornais utilizados neste artigo publicaram, durante o Carnaval, cadernos especiais sobre o evento, com a proposta de cobrir a programação, explicar os enredos das Escolas de Samba e dar dicas de como chegar aos lugares. $\mathrm{O}$ assunto violência não faz parte desse repertório. No entanto, esse assunto tão cultuado pela mídia impressa carioca também não foi devidamente contemplado no restante dos dois jornais, sobretudo, nos espaços em que costuma ser pauta de várias matérias, como a primeira página e o caderno ou editoria de Cidade. Por ser tratar de um megaevento, é natural que ele seja o assunto principal, especialmente em uma festa que leva vários dias seguidos, como o Carnaval.

Podemos também observar que boa parte das matérias e dos artigos de opinião reforça a íntima relação que existe entre a cidade do Rio de Janeiro e os megaeventos. Reveillon, Carnaval, Rio-92, Pan, Copa, Jogos Olímpicos, Rio Fashion Week são alguns dos exemplos de cerimônias, celebrações, campeonatos e festas que acontecem na cidade, cada vez mais frequentemente. A mídia reforça, nesse caso, o que os políticos têm tentado fazer o povo acreditar: o Rio é uma cidade ideal para megaeventos.

O fermento social proveniente de ajuntamentos de pessoas de diferentes procedências forma o ambiente para uma nova concepção de comunidade e de esfera pública que predomina nos megaeventos. O Carnaval carioca privilegia uma impressionante pluralidade de imagens motivando a construção de redes de comunicação nas quais cada ator representa vários personagens ao mesmo tempo. Poderia-se arriscar a falar de um certo "narcisismo coletivo" - "reconhecemo-nos no outro, a partir do outro" (MAFFESOLI, 1990: 35) - que se pulveriza entre os públicos do Carnaval no Rio de Janeiro, mas, sobretudo, através das máscaras e de todo o aparathus estheticus da pós-modernidade. Na década de 80, Baudrillard defendia que a sociedade caminhava para um desinvestimento do sistema dos objetos em favor de uma hiperrealidade onde as coisas e as pessoas misturam-se em terminais de múltiplas redes: "Hoje, nem palco nem espelho, mas uma tela e uma rede. Nem transcendência nem profundidade, mas (...) a superfície lisa e operacional da comunicação" (BAUDRILLARD, 1987: 12). O quadro, vinte anos depois, não é muito diferente do que comentava Baudrillard. Os objetos são cada vez mais efêmeros, apesar de estarem, como 
nunca, impregnados ao imaginário do cotidiano urbano, o qual, sem comunicação, não parece ter mais sentido. Ao mesmo tempo, percebemos que o megaevento aqui estudado se inscreveu em um imaginário de tradição que cresce a cada ano, sugerindo o retorno do palco e do espelho.

Apesar de o homem contemporâneo ter se acostumado a perceber o outro através de máquinas (telefone, televisão, Internet) e dentro de novos espaços (shopping centers, condomínios fechados, centros empresariais), ele continua querendo ou precisando viver em contato direto com diferentes pessoas, mesmo que seja de forma efêmera, na qual o espetáculo é um dos ambientes que as une. Os megaeventos são ótimos espaços de vivência para essa união sem vínculos.

\section{Bibliografia:}

ANTUNES, Elton \& VAZ, Paulo Bernardo. "Mídia: um aro, um halo e um elo". In: Na mídia, na rua: narrativas do cotidiano. GUIMARÃES, César \& FRANÇA, Vera (orgs.). Belo Horizonte: Autêntica, 2006.

BAUDRILLARD, Jean. La transparence du mal - Essai sur les phénomènes extrêmes. Paris: Galilée, 1990.

\section{. L'autre par lui-même. Paris: Galilée, 1987.}

BAUMAN, Zygmunt. A sociedade individualizada: vidas contadas e histórias vividas. Rio de Janeiro: Zahar, 2008.

CERTEAU, Michel de. A invenção do cotidiano 1: artes de fazer. Petrópolis: Vozes, 1994.

CHARTIER, Roger. História cultural: entre práticas e representações. Rio de Janeiro: Bertrand Brasil, 1988.

CONTRERA, Malena \& MORO, Marcela. "Vertigem mediática nos megaeventos musicais". Revista ECompós. Brasília, v. 11, jan.-abr. de 2008.

DURKHEIM, Émile. As formas elementares de vida religiosa. São Paulo: Paulus, 1989.

MAFFESOLI, Michel. A parte do diabo: resumo da subversão pós-moderna. Rio de Janeiro: Record, 2004.

. Au creux des apparences: pour une éthique de l'esthétique. Paris: Plon, 1990.

O ritmo da vida: variações sobre o imaginário pós-moderno. Rio de Janeiro: Record, 2007.

MAUSS, Marcel. Sociologie et anthropologie. Paris: Quadrige/PUF, 1991.

MEIRELES, Cecília. Flor de poemas. Rio de Janeiro: Nova Fronteira, 1972.

RAMOS, Silvia \& PAIVA, Anabela (org.). Mídia e violência: novas tendências na cobertura de criminalidade e segurança no Brasil. Rio de Janeiro: IUPERJ, 2007. 


\section{Notas:}

Artigo apresentado no Grupo de Trabalho Cultura das Mídias no XIX Encontro da Compós, PUC-RJ, em junho de 2010.

\section{Mini Currículo :}

Doutor em sociologia, com pós-doutorado em comunicação pela Universidade Paris V-Sorbonne. Professor adjunto da Faculdade de Comunicação Social da Universidade Estadual do Rio de Janeiro (UERJ). 